\title{
An Immunoaffinity Purification Method for the Simultaneous Analysis of Triclocarban and Triclosan in Foodstuffs by Liquid Chromatography Tandem Mass Spectrometry
}

Kai Yao ${ }^{\dagger,}$, Kai Wen ${ }^{\dagger}$, Wenchong Shan ${ }^{\dagger,}$, Haiyang Jiang ${ }^{\dagger}$, Bing Shao ${ }^{*}, \dagger$,

$\dagger$ Beijing Advanced Innovation Center for Food Nutrition and Human Health, College of Veterinary Medicine, China Agricultural University, Beijing 100193, People's Republic of China

¥ Beijing Key Laboratory of Diagnostic and Traceability Technologies for Food Poisoning, Beijing Center for Disease Prevention and Control, 100013, People's Republic of China 
ELISA procedure. Coating antigen $(100 \mu \mathrm{L}$ per well) diluted with coating buffer (13 $\mathrm{mM} \mathrm{Na}_{2} \mathrm{CO}_{3}$ and $35 \mathrm{mM} \mathrm{NaHCO}$, $\mathrm{pH}$ 9.6) was added to 96-well plates and incubated overnight at $4{ }^{\circ} \mathrm{C}$. After the plates were washed three times with washing buffer [0.01 mol/L phosphate buffer saline (PBS), pH 7.4, 0.05\% Tween 20], the unbound active sites in the wells were blocked with $150 \mu \mathrm{L}$ blocking buffer $(0.01$ $\mathrm{mol} / \mathrm{L}$ phosphate buffered saline, $\mathrm{pH} 7.4$, containing $0.5 \%$ BSA, and $0.05 \%$ Tween 20 ) for $1 \mathrm{~h}$ at $37^{\circ} \mathrm{C}$. The plates were washed three times with washing buffer, then dried for $1 \mathrm{~h}$ at $37^{\circ} \mathrm{C}$. Fifty microliters of antibody dilution in PBS was added to the wells together with $50 \mu \mathrm{L}$ TCC, TCS or related compounds standard solution, followed by incubation for $30 \mathrm{~min}$ at $37^{\circ} \mathrm{C}$. After the plates were washed five times with washing buffer, $100 \mu \mathrm{L}$ peroxidase-labeled goat anti-rabbit immunoglobulins was added to the wells, followed by incubation for $30 \mathrm{~min}$ at $37^{\circ} \mathrm{C}$. The plates were washed five times with washing buffer, $100 \mu \mathrm{L}$ TMB substrate solution was added to the wells, followed by incubation for $10 \mathrm{~min}$ at $37^{\circ} \mathrm{C}$. Finally, a $50 \mu \mathrm{L}$ stop solution $\left(2 \mathrm{~mol} / \mathrm{L} \mathrm{H}_{2} \mathrm{SO}_{4}\right)$ was added to the wells to stop the enzymatic reaction, and absorbance at $450 \mathrm{~nm}$ was measured with a Spectramax M5 microplate reader (Sunnyvale, CA, USA). 
Table S1 Cross-reactivity of compounds structurally similar to TCC

Compounds Cross-reactivity ${ }^{\mathrm{a}}$ (\%)

${ }^{\mathrm{a}}$ Cross-reactivity $=\left(\mathrm{IC}_{50}\right.$ of $\mathrm{TCC} / \mathrm{IC}_{50}$ of related compound $) \times 100 \%$. 
Table S2 Cross-reactivity of compounds structurally similar to TCS

Compounds Cross-reactivity ${ }^{\mathrm{a}}$ (\%)

${ }^{\mathrm{a}}$ Cross-reactivity $=\left(\mathrm{IC}_{50}\right.$ of $\mathrm{TCS} / \mathrm{IC}_{50}$ of related compound $) \times 100 \%$. 